\title{
The putative role of the venous system in the genesis of vascular malformations
}

\author{
Mariam S. Aboian, Ph.D., ${ }^{1}$ David J. Daniels, M.D., Ph.D., ${ }^{2}$ Stylianos K. Rammos, M.D., ${ }^{3}$ \\ Eugenio Pozzati, M.D., ${ }^{4}$ And Giuseppe Lanzino, M.D. ${ }^{2}$ \\ ${ }^{1}$ Mayo Clinic College of Medicine, and ${ }^{2}$ Department of Neurologic Surgery, Mayo Clinic, Rochester, \\ Minnesota; ${ }^{3}$ Department of Neurosurgery, Illinois Neurological Institute, University of Illinois College of \\ Medicine at Peoria, Illinois; and ${ }^{4}$ Department of Neurosurgery, Sections of Neuroradiology and Pathology, \\ Bellaria Hospital, Bologna, Italy
}

\begin{abstract}
Recent clinical and experimental evidence has challenged the traditional concept of the venous system as a "passive" element in the genesis and evolution of intracranial vascular malformations. The authors review the clinical and experimental evidence linking the venous system and its anomalies to the genesis of various intracranial vascular malformations, including dural arteriovenous fistulas, cavernous malformations, parenchymal arteriovenous malformations, and capillary telangiectasia. They also describe the potential significance of different associations of these vascular anomalies. (DOI: 10.3171/2009.8.FOCUS09161)
\end{abstract}

\section{KeY WORDS - vascular malformation - arteriovenous malformation • dural arteriovenous fistula $\bullet \quad$ cavernous malformation • telangiectasia}

$\mathrm{I}$ NTRACRANIAL vascular malformations represent a heterogeneous group of lesions classically classified by McCormick ${ }^{41}$ into 4 major groups: arteriovenous malformations, cavernous malformations, venous angiomas, and capillary telangiectasia. These vascular anomalies were once considered uncommon. However, the routine use of MR imaging has demonstrated a higher incidence than originally considered. In addition, the observation that some of these malformations can occur in association has raised questions about a potential common genesis. Although the venous system was traditionally considered a "passive" component of vascular malformations, recent evidence suggests an increasing potential role of the venous system and its anomalies in the genesis of these lesions. In this report, we outline the current knowledge about the mutual relationships between the venous system and the genesis of vascular malformations and speculate about possible further developments in the understanding of this complicated but fascinating evolving chapter in vascular neurosurgery.

\section{Dural Arteriovenous Fistulas}

It is well accepted that the venous system and its anomalies play an important role in the formation of intracranial DAVFs. Dural arteriovenous fistulas are abnor-

Abbreviations used in this paper: AVM = arteriovenous malformation; $\mathrm{CM}=$ cavernous malformation; $\mathrm{DAVF}=$ dural arteriovenous fistula; DVA = developmental venous anomaly. mal connections between meningeal arteries and dural veins and account for approximately $10-15 \%$ of all intracranial vascular malformations. ${ }^{3,31,35,48}$ Originally, they were thought to be congenital in nature; however, growing evidence in the past 30 years has shown that they are acquired lesions often resulting from impaired venous outflow. Symptomatic patients with DAVFs present at an older age with pulsatile tinnitus, headache, visual impairment, intracranial hemorrhage, focal or generalized neurological deficits, seizures, and altered mental status. ${ }^{12,63,70}$ Morbidity correlates more with the severity of DAVF retrograde cortical venous reflux as classified by the Borden and Cognard grading systems, and not necessarily the location of the DAVF. $4,10,15,24,34$ In patients with DAVFs with cortical venous reflux, the annual rate of intracranial hemorrhage or nonhemorrhagic neurological deficit is $15-19 \% .{ }^{63,70}$ Dural arteriovenous fistulas without cortical venous reflux, have a low risk of hemorrhage $^{14,19}$ and have been reported to undergo spontaneous regression. ${ }^{38}$

In 1972, Houser et al. ${ }^{24}$ observed the development of DAVFs in patients with previous venous thrombosis documented by catheter angiography. Since then, this observation has been corroborated by other authors, $7,9,11,25,32,36,44,65,68$ and preexisting dural sinus thrombosis is considered the basis for the formation of the majority of DAVFs associated with major intracranial venous sinuses.

The etiology of sinus thrombosis includes a variety of causes that are either acquired or congenital, including 
trauma, surgical infections, and various thrombophilic conditions. Procoagulative states can be due to a genetic defect of a coagulative pathway or can be acquired, as in pregnancy or during oral contraceptive therapy. Heritable risk factors for sinus thrombosis include factor $\mathrm{V}$ Leiden mutation, prothrombin G20210A mutation, and protein $\mathrm{C}$ and protein $\mathrm{S}$ deficiencies. . $^{13,21,29,30,33,40,57,58,72-74,77}$ Since preexisting sinus thrombosis is related to the subsequent development of DAVFs, recent studies have suggested an association between such inherited prothrombotic states and DAVFs.

Gerlach et al. ${ }^{21}$ showed that genetic thrombophilic abnormalities occur in a higher percentage of patients with DAVFs than in the general population. Furthermore, they proposed that the differences in genetic abnormalities may be involved in different pathophysiological mechanisms resulting in cranial versus spinal DAVFs. Specifically, they found that the prevalence of the G20210A prothrombin mutation was almost 10 -fold higher in patients with cranial DAVFs compared with the general population, whereas in patients with spinal DAVFs the prevalence of factor $\mathrm{V}$ Leiden mutation was increased about 3-fold. Other reports have implicated factor $\mathrm{V}$ Leiden mutation in the etiopathogenesis of DAVFs. ${ }^{21,30,56,71,72}$ Kraus and colleagues ${ }^{29,30}$ have observed increased prevalence of factor $\mathrm{V}$ Leiden mutation but not of other genetic thrombophilic anomalies with DAVFs. Severity of DAVF symptoms was higher in patients with activated protein $\mathrm{C}$ resistance as compared with patients without thrombophilia. ${ }^{30}$ Other thrombophilias, such as protein S deficiency and antithrombin III deficiency, have been found in patients with DAVFs, further strengthening a causal relationship between anomalies (prothrombotic states) involving the venous system and the genesis of DAVFs. Protein S deficiency has been shown in a child with a DAVF and venous sinus thrombosis,${ }^{74}$ and development of multiple DAVFs has been found in a patient with antithrombin III deficiency. ${ }^{57}$ Importantly, prothrombotic states preferentially involving the arterial system have not been shown to be increased in patients with DAVFs. ${ }^{29}$ This observation, again, implicates the venous system and in particular intracranial venous sinus thrombosis in the formation of DAVFs.

The exact mechanisms triggering the formation and progression of arteriovenous dural shunts in patients with preexisting sinus thrombosis is unknown and likely multifactorial. Initial studies proposed that inflammation related to sinus thrombosis and the subsequent recanalization of the sinus may be responsible for DAVF formation. This inflammatory response was proposed to initiate angiogenic activity and lead to fistula formation between the arterial supply of the dura and the venous sinuses. ${ }^{25,64}$ This hypothesis, though, does not explain the formation of DAVFs distant to the venous sinus thrombosis. Animal models have confirmed that sinus thrombosis and the resulting elevation in sinus pressure may lead to the formation of DAVFs. ${ }^{36,57,74}$ In an elegant experiment, Lawton and coworkers ${ }^{36}$ demonstrated that in rats, increased venous pressure was related to increased angiogenic activity and both led to the formation of both dural AVFs and facial AVMs in rats. Other authors have confirmed a

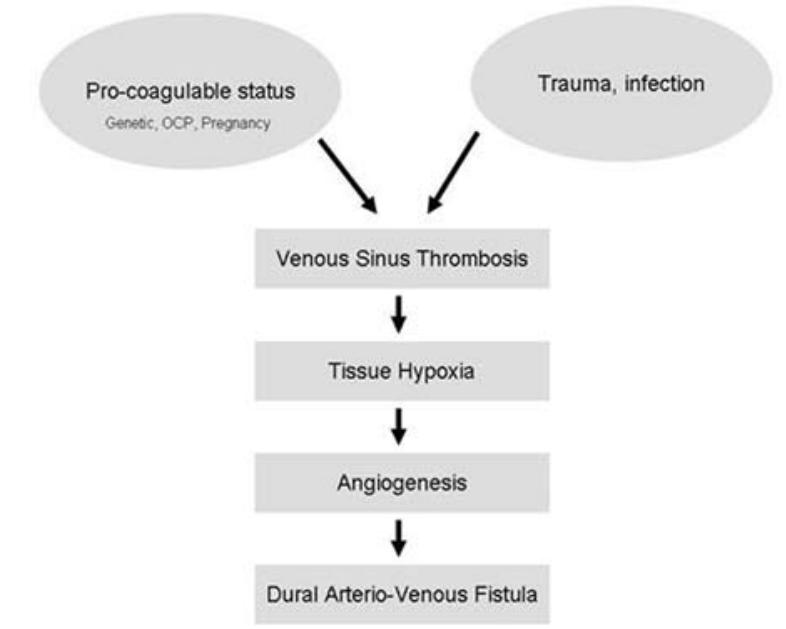

FIG. 1. Model for formation of DAVFs.

causal role of both sinus thrombosis and venous hypertension in the genesis of DAVFs. ${ }^{29,53,54,57,64,74}$ In one such study, Herman et al. ${ }^{22}$ showed that sinus thrombosis associated with sinus hypertension leads to the formation of DAVFs, while sinus occlusion without venous hypertension did not. This is clinically collaborated by the fact that very few patients with surgical occlusion of the sigmoid sinus develop DAVFs. ${ }^{61}$ Furthermore, through molecular studies it has been shown that venous hypertension induces angiogenic activity either directly or indirectly by decreasing cerebral perfusion and increasing ischemia and that aberrant angiogenesis is responsible for DAVF formation. ${ }^{32,36,69}$

We can conclude that DAVFs are acquired vascular malformations that arise from impaired venous outflow most commonly due to sinus thrombosis. This in turn leads to venous hypertension and resulting tissue hypoxia and activation of angiogenesis, leading to eventual formation of DAVFs (Fig. 1). Hypercoagulable states predispose patients to venous sinus thrombosis and can occur after acquired conditions such as trauma or infection or in genetic conditions that result in thrombophilia.

\section{Developmental Venous Anomalies}

Developmental venous anomalies are also known in the literature as venous anomalies, venous angiomas, and venous caput medusae. ${ }^{53}$ These venous malformations drain normal parenchymal tissue with functionally normal arterial anatomy and lack of abnormal arteriovenous shunting. Developmental venous anomalies are common and constitute $60 \%$ of intracranial vascular malformations. ${ }^{54}$ On angiograms they appear as radially arranged medullary veins with a central draining trunk, an abnormality of cerebral surface veins, and a "star cluster" appearance of draining veins ${ }^{46}$ Although, they have been reported to be associated with intracranial hemorrhage, seizures, and progressive neurological defects, the risk of significant hemorrhage is negligible $(0.22-0.68 \%),{ }^{18,20,43,50}$ and current recommendations strongly suggest conservative management of these lesions. ${ }^{28}$ With the widespread availability of MR imaging, DVAs are frequently encoun- 


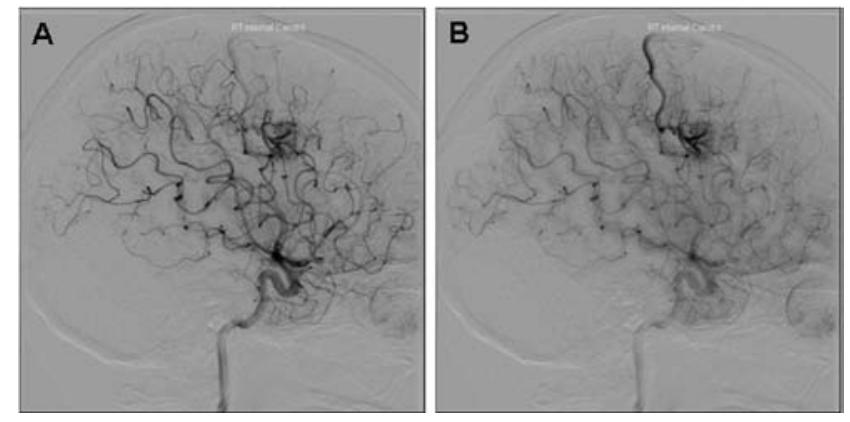

FIG. 2. Mixed AVM-DVA in a 48-year-old woman who presented with hemorrhage. $\quad A$ and $B$ : Midarterial phase $(A)$ and late arterial phase (B) angiograms, right internal carotid artery injection, showing a diffuse AVM with a mixed DVA component.

tered in association with other vascular malformations particularly CMs and less commonly parenchymal AVMs and capillary telangiectasia. When DVAs are associated with neurological symptoms, these are usually ascribed to the coexisting vascular malformations. The frequent coexistence of DVAs with other vascular malformations has led to speculations regarding their potential causal role in the genesis and progression of the associated vascular anomalies. ${ }^{53}$

\section{Venous Predominant Parenchymal AVMs}

Venous predominant parenchymal AVMs are also known as atypical DVAs or arterialized venous malformations. ${ }^{26}$ These malformations are characterized by the presence of a DVA (caput medusae with a large draining vein) associated with arteriovenous shunts, without a classic AVM nidus on angiography. ${ }^{2,23}$ Magnetic resonance imaging findings include contrast-enhancing dilated medullary veins in a spoke-wheel pattern and an enlarged central draining vein, ${ }^{37}$ which can easily be mistaken for developmental venous anomalies on MR imaging alone (Fig. 2). The clinical presentation associated with these lesions is nonspecific. In the largest study of these malformations, 6 of 13 patients had an incidental finding of the venous predominant parenchymal AVM, while 8 presented with intracranial hemorrhage, and 1 patient presented with seizures. ${ }^{26}$ Therefore, a high index of clinical suspicion needs to be present to proceed to angiography after MR imaging. ${ }^{26,75}$ Correct diagnosis of these lesions is important because incomplete removal of the arterialized feeding vessels or occlusion of only the main draining vein can lead to postoperative hemorrhage as in 2 of 15 patients in the case series reported by Im and coauthors. ${ }^{26,75}$

The association of DVAs with arteriovenous shunts in "venous-predominant" AVMs suggests that these forms may be transitions in a spectrum evolving from the original DVA to the "mature" AVM. Mullan and cowork$\mathrm{ers}^{47}$ have proposed that the DVA may serve as a skeleton for future AVM development and, in fact, the AVM may merely represent a fistulized DVA. In such a hypothetical model, the proposed formation of the AVM parallels DAVF development: thrombosis and subsequent partial recanalization of the DVA rootlets may induce arterializations of the DVA, creating the basis for a newly formed AVM. ${ }^{45-47}$ Indeed, in a very interesting case report, Nussbaum and coworkers ${ }^{49}$ documented development of multiple AVMs in the proximity of a DVA.

These hypotheses and examples, while stressing the potential important role of the venous system in the genesis of AVMs, challenge the traditional concept of parenchymal AVMs as congenital lesions. However, several recent clinical and anecdotal observations support the view that even parenchymal AVMs may not be congenital. Increasing reports are clearly documenting de novo formation of parenchymal AVMs. ${ }^{49,62}$ Large AVMs-at times involving an entire hemisphere-are not that uncommon and yet, while vein of Galen AVMs are commonly detected in utero with modern ultrasound, there are only scant reports of parenchymal AVMs detected with this increasingly sophisticated prenatal diagnostic imaging method. ${ }^{16}$ Nevertheless, in the cases so far documented of de novo AVM formation (except for the one reported by Nussbaum et al.), no DVA was evident. We speculate that similar to preexisting dural sinus thrombosis, parenchymal vein thrombosis (which unlike dural sinus thrombosis may often go undiagnosed because of being asymptomatic or oligosymptomatic) could be the trigger for local venous hypertension and ischemia, which in turn leads to increased vascular endothelial growth factor (VEGF) production and aberrant angiogenesis resulting in the development of the parenchymal AVM. Indeed, patients with AVMs have been observed to have significantly increased levels of VEGF when compared with a control group..$^{59}$
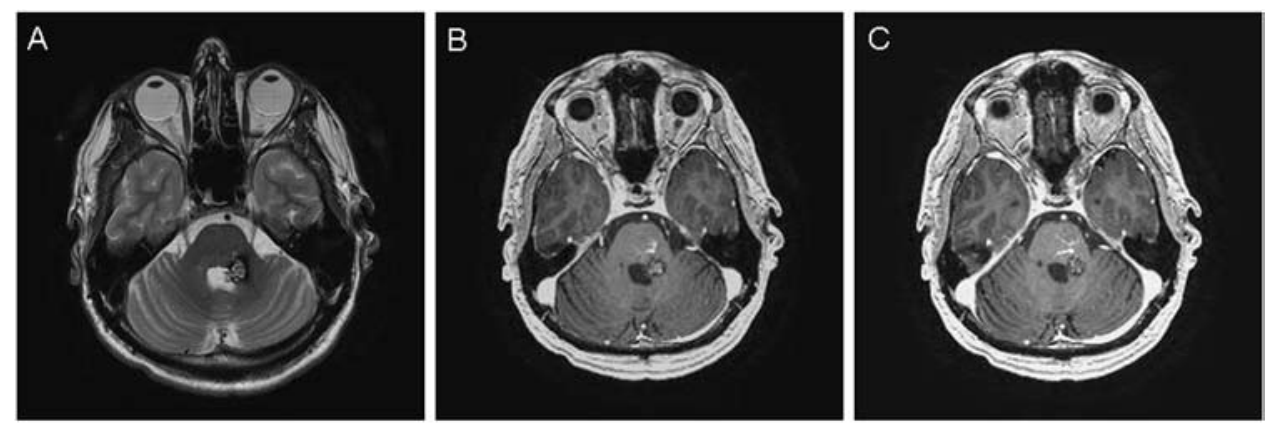

FIG. 3. Cavernous malformation of the cerebellar peduncle and an associated DVA. A: A T2-weighted MR image showing a CM. B and C: Gadolinium-enhanced T1-weighted MR images showing the CM and adjacent DVA in a "star cluster" appearance. 
TABLE 1: Incidence of coinciding CMs and DVAs in series of cases of CMs and DVAs*

\begin{tabular}{lcc}
\hline \multicolumn{1}{c}{ Authors \& Year } & (CM + DVA)/CM & (CM + DVA)/DVA \\
\hline Awad et al., 1993 & $6 / 11(55)$ & \\
Ostertun \& Solymos, 1993 $\dagger$ & & $7 / 21(33)$ \\
Wilms et al., 1994 & $15 \S$ & \\
Huber et al., 1996ף & & $17 / 43(40)$ \\
Topper et al., 1999 & & $12 / 67(18)$ \\
Abdulrauf et al., 1999 & $13 / 55(24)$ & \\
Porter et al., 1999 & $86 / 100(86)$ & \\
Wurm et al., 2005 & $15 / 58(25.9)$ & \\
Kamezawa et al., 2005 & $34 / 57(60)$ & \\
\hline
\end{tabular}

* Values represent numbers of cases of coinciding CMs and DVAs in series of cases of CMs (middle column) and cases of DVAs (right-hand column). Values in parentheses are the incidents rates (\%).

$\dagger$ Ostertun B, Solymos L: Magnetic resonance angiography of cerebral developmental venous anomalies: its role in differential diagnosis. Neuroradiology 35:97-104, 1993.

\$ Wilms G, et al: Simultaneous occurrence of developmental venous anomalies and cavernous angiomas. AJNR Am J Neuroradiol 15:12471257, 1994.

$\S$ All 15 cases involved coinciding CMs and DVAs.

I Huber G, et al: Regional association of developmental venous anomalies with angiographically occult vascular malformations. Eur Radiol 6:30-37, 1996

\section{Parenchymal DVAs Associated With CMs}

Coexistence of a DVA with a CM is common, with the association reported in 24-86\% of CMs (Table 1). ${ }^{1,51,55,76,77}$ A higher incidence of coinciding lesions (86\%) was found when postoperative pathology reports were included in the analysis, or when CT angiograms (60\%) were used as a diagnostic tool, ${ }^{27,51}$ as opposed to MR imaging alone. ${ }^{1}$ The radiological association between DVAs and CMs is much more commonly seen in infratentorial CMs (Fig. 3) than in their supratentorial counterparts (Fig. 4). Several reports have demonstrated de novo formation of a CM in the drainage territory of a DVA, thus suggesting that abnormal vascular anatomy of DVA may lead to the venous hypertension, which in turn leads to formation of the CM due to angiogenic proliferation..$^{2,5,6,39,73}$ This is otherwise known as the hemorrhagic angiogenic proliferation hypothesis. ${ }^{66}$ Several reports also showed an increased incidence (12.5-28.3\%) of white matter signal abnormalities proximal to a DVA on MR imaging, which leads to questioning whether these abnormalities are the early stages of CM development. ${ }^{58,60}$

Two different types of DVAs have been associated with CMs. The first type is characterized by classic venous drainage via a central vein, while the second type is characterized by atypical drainage that does not have any connection to the transcortical venous system. ${ }^{27,50}$ Whether there is a difference in symptoms or hemorrhage rates between the typical and atypical DVAs is unknown. Cavernous malformations associated with visible DVAs may have an increased incidence of hemorrhage and non- hemorrhagic neurological symptoms as compared with CMs without visible DVAs. The incidence rate of hemorrhage ranged from 62 to $93 \%$ in patients with CM with an associated DVA ${ }^{1,67,76}$ as compared with $38 \%$ in patients with CMs without visible DVAs ${ }^{1}$ or $0-0.68 \%$ in patients with DVA alone. ${ }^{18,20,43,50}$ Interestingly, no visible DVAs adjacent to CMs have been reported in patients with familial CMs, suggesting a different possible pathogenesis between the familial and the sporadic form. The potential role of DVAs in the genesis of CMs will be better clarified as we gain further understanding of the genetics and molecular biology of CMs.

\section{Parenchymal DVAs Associated With Capillary Telangiectasia and CMs}

Association of capillary telangiectasias with DVAs and/or CMs is rare..$^{8,17,42,52}$ Telangiectasia typically occurs in the pons and consists of dilated capillary spaces within normal parenchyma. This triad was initially characterized in a single patient with a complex constellation of neurological symptoms; the lesions were identified by MR imaging of the brainstem. ${ }^{8}$ This patient was followed up conservatively and did not present with hemorrhage at any time during the period of evaluation. ${ }^{8}$ In a study of 6 cases of this triad in the brainstem, all of the patients presented with acute neurological symptoms and the lesions were identified using post-Gd MR imaging. ${ }^{51}$ Three of these 6 patients presented with hemorrhage requiring surgical treatment, and in 2 of these 3, histopathological confirmation was obtained..$^{52}$ An example of a case involving a patient with a history of diplopia and MR imaging/histopathological confirmation of the triad of DVA, CM, and telangiectasia is presented in Fig. 4. These studies suggest that the mixed lesions comprising DVAs, capillary telangiectasia, and CMs have a more aggressive nature than the individual lesions alone as described above. Further characterization of this association will shed more light on the possible mutual interactions among the 3 different vascular anomalies.

\section{Conclusions}

In conclusion, growing evidence suggests an "active" role of the venous system in the genesis of various intracranial vascular malformations. In some lesions, such as DAVFs and CMs, this role is better defined and accepted, while in others, such as parenchymal AVMs, it is only putative and highly speculative. As more clinical and experimental evidence is collected, it is not difficult to anticipate further evolution of the causal role of the "venous side" in the genesis and evolution of these lesions. In the future, better understanding of this role may lead to a shift in the therapeutic targets and more precise prediction of clinical behavior in individual cases.

\section{Disclaimer}

The authors report no conflict of interest concerning the materials or methods used in this study or the findings specified in this paper. 

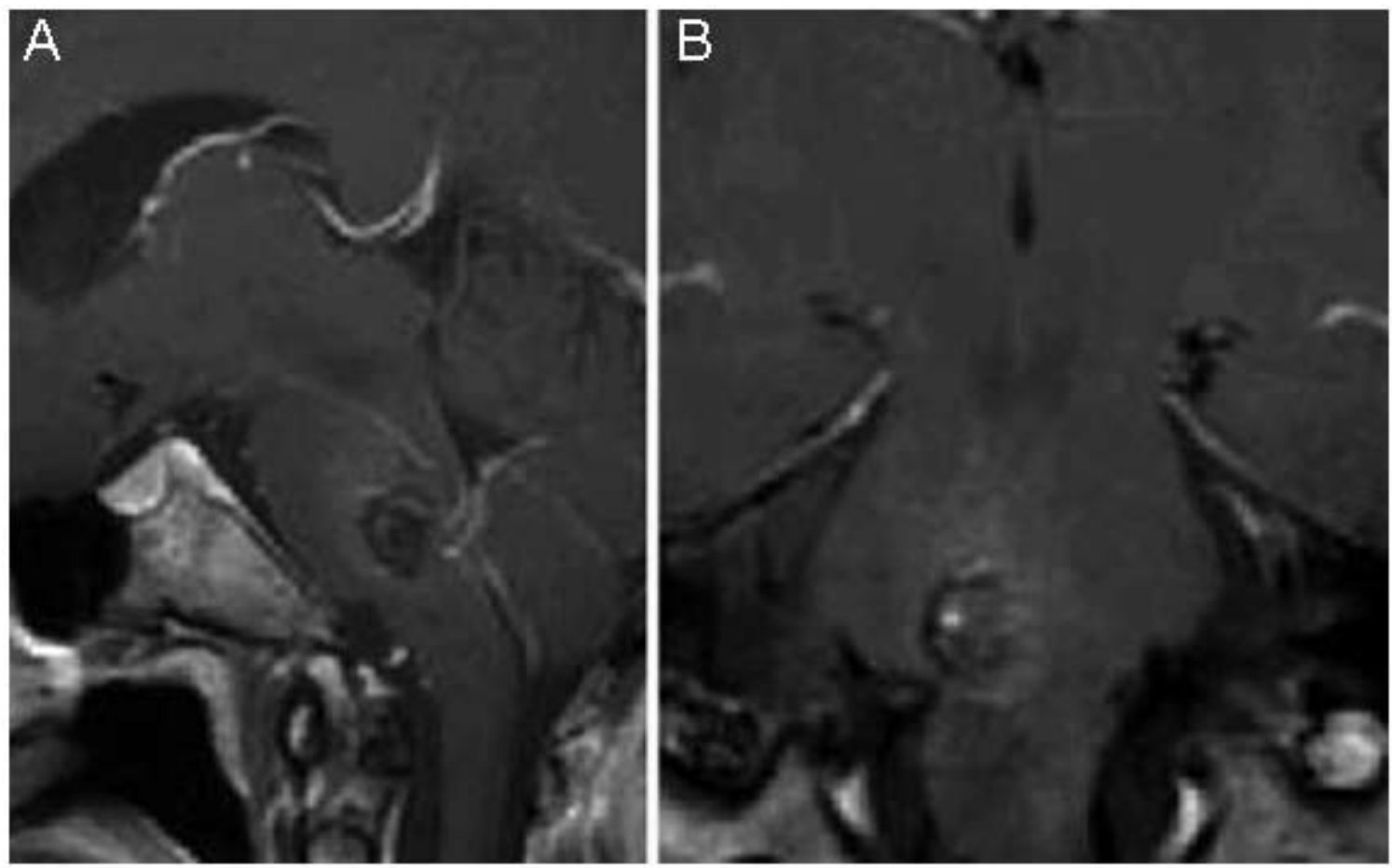

FIG. 4. Representative case of a coinciding DVA, telangiectasia, and CM. This 35-year-old woman presented with onset of double vision and a history of a single episode of diplopia when she was a child. Hemorrhage was observed on CT, and MR imaging demonstrated a mixed-signal intensity lesion surrounded by a hypointense rim consistent with the characteristics of a $\mathrm{CM}$. After Gd administration, a complex vascular malformation consisting of a DVA with multiple drainage channels through the pons and ventricular floor associated with a pontine telangiectasia became apparent. A and B: Sagittal (A) and coronal (B) fast spin echo T1-weighted MR images obtained after Gd administration revealing a CM surrounded by a capillary telangiectasia and a DVA, with multiple drainage channels through the pons. Reproduced with permission from Pozzati et al: $\mathbf{J}$ Neurosurg 107:1113-1119, 2007.

\section{References}

1. Abdulrauf SI, Kaynar MY, Awad IA: A comparison of the clinical profile of cavernous malformations with and without associated venous malformations. Neurosurgery 44:41-47, 1999

2. Awad IA, Robinson JR Jr, Mohanty S, Estes ML: Mixed vascular malformations of the brain: clinical and pathogenetic considerations. Neurosurgery 33:179-188, 1993

3. Barnwell SL, Halbach VV, Dowd CF, Higashida RT, Hieshima GB, Wilson CB: Multiple dural arteriovenous fistulas of the cranium and spine. AJNR Am J Neuroradiol 12:441-445, 1991

4. Borden JA, Wu JK, Shucart WA: A proposed classification for spinal and cranial dural arteriovenous fistulous malformations and implications for treatment. J Neurosurg 82:166179,1995

5. Cakirer S: De novo formation of a cavernous malformation of the brain in the presence of a developmental venous anomaly. Clin Radiol 58:251-256, 2003

6. Campeau NG, Lane JI: De novo development of a lesion with the appearance of a cavernous malformation adjacent to an existing developmental venous anomaly. AJNR Am J Neuroradiol 26:156-159, 2005

7. Chaudhary MY, Sachdev VP, Cho SH, Weitzner I Jr, Puljic S, Huang YP: Dural arteriovenous malformation of the major venous sinuses: an acquired lesion. AJNR Am J Neuroradiol 3:13-19, 1982

8. Clatterbuck RE, Elmaci I, Rigamonti D: The juxtaposition of a capillary telangiectasia, cavernous malformation, and developmental venous anomaly in the brainstem of a single patient: case report. Neurosurgery 49:1246-1250, 2001
9. Cognard C, Casasco A, Toevi M, Houdart E, Chiras J, Merland JJ: Dural arteriovenous fistulas as a cause of intracranial hypertension due to impairment of cranial venous outflow. J Neurol Neurosurg Psychiatry 65:308-316, 1998

10. Cognard C, Gobin YP, Pierot L, Bailly AL, Houdart E, Casasco A, et al: Cerebral dural arteriovenous fistulas: clinical and angiographic correlation with a revised classification of venous drainage. Radiology 194:671-680, 1995

11. Cognard C, Houdart E, Casasco A, Gabrillargues J, Chiras J, Merland JJ: Long-term changes in intracranial dural arteriovenous fistulae leading to worsening in the type of venous drainage. Neuroradiology 39:59-66, 1997

12. Cordonnier C, Al-Shahi Salman R, Bhattacharya JJ, Counsell CE, Papanastassiou V, Ritchie V, et al: Differences between intracranial vascular malformation types in the characteristics of their presenting haemorrhages: prospective, population-based study. J Neurol Neurosurg Psychiatry 79:47-51, 2008

13. Dahlback B, Carlsson M, Svensson PJ: Familial thrombophilia due to a previously unrecognized mechanism characterized by poor anticoagulant response to activated protein $\mathrm{C}$ : prediction of a cofactor to activated protein C. Proc Natl Acad Sci U S A 90:1004-1008, 1993

14. Davies MA, Saleh J, TerBrugge K, Willinsky R, Wallace MC: The natural history and management of intracranial dural arteriovenous fistulae. Part 1: benign lesions. Intervent Neuroradiol 3:295-302, 1997

15. Davies MA, TerBrugge K, Willinsky R, Coyne T, Saleh J, Wallace MC: The validity of classification for the clinical presentation of intracranial dural arteriovenous fistulas. J Neurosurg 85:830-837, 1996 
16. DeCesare B, Omojola MF, Fogarty EF, Brown JC, Taylon C: Spontaneous thrombosis of congenital cerebral arteriovenous malformation complicated by subdural collection: in utero detection with disappearance in infancy. Br J Radiol 79:e140e144, 2006

17. Diamond C, Torvik A, Amundsen P: Angiographic diagnosis of teleangiectases with cavernous angioma of the posterior fossa. Report of two cases. Acta Radiol Diagn (Stockh) 17:281-288, 1976

18. Duffau H, Lopes M, Janosevic V, Sichez JP, Faillot T, Capelle L, et al: Early rebleeding from intracranial dural arteriovenous fistulas: report of 20 cases and review of the literature. J Neurosurg 90:78-84, 1999

19. Fermand M, Reizine D, Melki JP, Riche MC, Merland JJ: Long term follow-up of 43 pure dural arteriovenous fistulae (AVF) of the lateral sinus. Neuroradiology 29:348-353, 1987

20. Garner TB, Del Curling O Jr, Kelly DL Jr, Laster DW: The natural history of intracranial venous angiomas. J Neurosurg 75:715-722, 1991

21. Gerlach R, Boehm-Weigert M, Berkefeld J, Duis J, Raabe A, Seifert V, et al: Thrombophilic risk factors in patients with cranial and spinal dural arteriovenous fistulae. Neurosurgery 63:693-699, 2008

22. Herman JM, Spetzler RF, Bederson JB, Kurbat JM, Zabramski JM: Genesis of a dural arteriovenous malformation in a rat model. J Neurosurg 83:539-545, 1995

23. Hirata Y, Matsukado Y, Nagahiro S, Kuratsu J: Intracerebral venous angioma with arterial blood supply: a mixed angioma. Surg Neurol 25:227-232, 1986

24. Houser OW, Baker HL Jr, Rhoton AL Jr, Okazaki H: Intracranial dural arteriovenous malformations. Radiology 105:5564,1972

25. Houser OW, Campbell JK, Campbell RJ, Sundt TM Jr: Arteriovenous malformation affecting the transverse dural venous sinus-an acquired lesion. Mayo Clin Proc 54:651-661, 1979

26. Im SH, Han MH, Kwon BJ, Ahn JY, Jung C, Park SH, et al: Venous-predominant parenchymal arteriovenous malformation: a rare subtype with a venous drainage pattern mimicking developmental venous anomaly. J Neurosurg 108:1142-1147, 2008

27. Kamezawa T, Hamada J, Niiro M, Kai Y, Ishimaru K, Kuratsu $\mathrm{J}$ : Clinical implications of associated venous drainage in patients with cavernous malformation. $\mathbf{J}$ Neurosurg 102:24-28, 2005

28. Kondziolka D, Dempsey PK, Lunsford LD: The case for conservative management of venous angiomas. Can J Neurol Sci 18:295-299, 1991

29. Kraus JA, Stuper BK, Muller J, Nahser HC, Klockgether T, Berlit P, et al: Molecular analysis of thrombophilic risk factors in patients with dural arteriovenous fistulas. J Neurol 249:680-682, 2002

30. Kraus JA, Stuper BK, Nahser HC, Klockgether T, Berlit P: Significantly increased prevalence of factor $\mathrm{V}$ Leiden in patients with dural arteriovenous fistulas. J Neurol 247:521523,2000

31. Kubota Y, Ueda T, Kaku Y, Sakai N: Development of a dural arteriovenous fistula around the jugular valve after transvenous embolization of cavernous dural arteriovenous fistula. Surg Neurol 51:174-176, 1999

32. Kurata A, Miyasaka Y, Yoshida T, Kunii M, Yada K, Kan S: Venous ischemia caused by dural arteriovenous malformation. Case report. J Neurosurg 80:552-555, 1994

33. Kurnik K, Kosch A, Strater R, Schobess R, Heller C, NowakGottl U: Recurrent thromboembolism in infants and children suffering from symptomatic neonatal arterial stroke: a prospective follow-up study. Stroke 34:2887-2892, 2003

34. Kwon BJ, Han MH, Kang HS, Chang KH: MR imaging findings of intracranial dural arteriovenous fistulas: relations with venous drainage patterns. AJNR Am J Neuroradiol 26:2500-2507, 2005

35. Lasjaunias P, Chiu M, ter Brugge K, Tolia A, Hurth M, Bernstein M: Neurological manifestations of intracranial dural arteriovenous malformations. J Neurosurg 64:724-730, 1986

36. Lawton MT, Jacobowitz R, Spetzler RF: Redefined role of angiogenesis in the pathogenesis of dural arteriovenous malformations. J Neurosurg 87:267-274, 1997

37. Lee C, Pennington MA, Kenney CM III: MR evaluation of developmental venous anomalies: medullary venous anatomy of venous angiomas. AJNR Am J Neuroradiol 17:61-70, 1996

38. Luciani A, Houdart E, Mounayer C, Saint Maurice JP, Merland JJ: Spontaneous closure of dural arteriovenous fistulas: report of three cases and review of the literature. AJNR Am J Neuroradiol 22:992-996, 2001

39. Maeder P, Gudinchet F, Meuli R, de Tribolet N: Development of a cavernous malformation of the brain. AJNR Am J Neuroradiol 19:1141-1143, 1998

40. Martinelli I, Landi G, Merati G, Cella R, Tosetto A, Mannucci PM: Factor $\mathrm{V}$ gene mutation is a risk factor for cerebral venous thrombosis. Thromb Haemost 75:393-394, 1996

41. McCormick WF: The pathology of vascular "arteriovenous" malformations. J Neurosurg 24:807-816, 1966

42. McCormick PW, Spetzler RF, Johnson PC, Drayer BP: Cerebellar hemorrhage associated with capillary telangiectasia and venous angioma: a case report. Surg Neurol 39:451-457, 1993

43. McLaughlin MR, Kondziolka D, Flickinger JC, Lunsford S, Lunsford LD: The prospective natural history of cerebral venous malformations. Neurosurgery 43:195-201, 1998

44. Mironov A: Dural arteriovenous fistula of the inferior petrosal sinus producing contralateral exophthalmus. Neuroradiology 36:619-621, 1994

45. Mullan S: Reflections upon the nature and management of intracranial and intraspinal vascular malformations and fistulae. J Neurosurg 80:606-616, 1994

46. Mullan S, Mojtahedi S, Johnson DL, Macdonald RL: Cerebral venous malformation-arteriovenous malformation transition forms. J Neurosurg 85:9-13, 1996

47. Mullan S, Mojtahedi S, Johnson DL, Macdonald RL: Embryological basis of some aspects of cerebral vascular fistulas and malformations. J Neurosurg 85:1-8, 1996

48. Newton TH, Cronqvist S: Involvement of dural arteries in intracranial arteriovenous malformations. Radiology 93:10711078, 1969

49. Nussbaum ES, Heros RC, Madison MT, Awasthi D, Truwit CL: The pathogenesis of arteriovenous malformations: insights provided by a case of multiple arteriovenous malformations developing in relation to a developmental venous anomaly. Neurosurgery 43:347-352, 1998

50. Perrini P, Lanzino G: The association of venous developmental anomalies and cavernous malformations: pathophysiological, diagnostic, and surgical considerations. Neurosurg Focus 21(1):e5, 2006

51. Porter RW, Detwiler PW, Spetzler RF, Lawton MT, Baskin JJ, Derksen PT, et al: Cavernous malformations of the brainstem: experience with 100 patients. J Neurosurg 90:50-58, 1999

52. Pozzati E, Marliani AF, Zucchelli M, Foschini MP, Dall'Olio M, Lanzino G: The neurovascular triad: mixed cavernous, capillary, and venous malformations of the brainstem. J Neurosurg 107:1113-1119, 2007

53. Rammos SK, Maina R, Lanzino G: Developmental venous anomalies: current concepts and implications for management. Neurosurgery 65:20-30, 2009

54. Rigamonti D, Spetzler RF, Medina M, Rigamonti K, Geckle DS, Pappas C: Cerebral venous malformations. J Neurosurg 73:560-564, 1990

55. Roberson GH, Kase CS, Wolpow ER: Telangiectases and cav- 
ernous angiomas of the brainstem: "cryptic" vascular malformations. Report of a case. Neuroradiology 8:83-89, 1974

56. Safavi-Abbasi S, Di Rocco F, Nakaji P, Feigl GC, Gharabaghi A, Samii M, et al: Thrombophilia due to Factor V and Factor II mutations and formation of a dural arteriovenous fistula: case report and review of a rare entity. Skull Base 18:135-143, 2008

57. Saito A, Takahashi N, Furuno Y, Kamiyama H, Nishimura $\mathrm{S}$, Midorikawa $\mathrm{H}$, et al: Multiple isolated sinus dural arteriovenous fistulas associated with antithrombin III deficiencycase report. Neurol Med Chir (Tokyo) 48:455-459, 2008

58. San Millan Ruiz D, Delavelle J, Yilmaz H, Gailloud P, Piovan E, Bertramello A, et al: Parenchymal abnormalities associated with developmental venous anomalies. Neuroradiology 49:987-995, 2007

59. Sandalcioglu IE, Wende D, Eggert A, Muller D, Roggenbuck U, Gasser T, et al: Vascular endothelial growth factor plasma levels are significantly elevated in patients with cerebral arteriovenous malformations. Cerebrovasc Dis 21:154-158, 2006

60. Santucci GM, Leach JL, Ying J, Leach SD, Tomsick TA: Brain parenchymal signal abnormalities associated with developmental venous anomalies: detailed MR imaging assessment. AJNR Am J Neuroradiol 29:1317-1323, 2008

61. Spetzler RF, Daspit CP, Pappas CT: The combined supra- and infratentorial approach for lesions of the petrous and clival regions: experience with 46 cases. J Neurosurg 76:588-599, 1992

62. Stevens J, Leach JL, Abruzzo T, Jones BV: De novo cerebral arteriovenous malformation: case report and literature review. AJNR Am J Neuroradiol 30:111-112, 2009

63. Strom RG, Botros JA, Refai D, Moran CJ, Cross DT III, Chicoine MR, et al: Cranial dural arteriovenous fistulae: asymptomatic cortical venous drainage portends less aggressive clinical course. Neurosurgery 64:241-248, 2009

64. Sundt TM Jr, Piepgras DG: The surgical approach to arteriovenous malformations of the lateral and sigmoid dural sinuses. J Neurosurg 59:32-39, 1983

65. Terada T, Higashida RT, Halbach VV, Dowd CF, Tsuura M, Komai N, et al: Development of acquired arteriovenous fistulas in rats due to venous hypertension. J Neurosurg 80:884889,1994

66. Thai QP, Pradilla G, Rigamonti D: Capillary telangiectasias, cavernous malformations, and developmental venous anoma- lies: different expressions of the same disease process? in Lanzino GS, Spetzler RF (eds): Cavernous Malformations of the Brain and Spinal Cord. New York: Thieme, 2008, pp 48-53

67. Topper R, Jurgens E, Reul J, Thron A: Clinical significance of intracranial developmental venous anomalies. J Neurol Neurosurg Psychiatry 67:234-238, 1999

68. Tsai LK, Jeng JS, Liu HM, Wang HJ, Yip PK: Intracranial dural arteriovenous fistulas with or without cerebral sinus thrombosis: analysis of 69 patients. J Neurol Neurosurg Psychiatry 75:1639-1641, 2004

69. Uranishi R, Nakase H, Sakaki T: Expression of angiogenic growth factors in dural arteriovenous fistula. J Neurosurg 91:781-786, 1999

70. van Dijk JM, terBrugge KG, Willinsky RA, Wallace MC: Clinical course of cranial dural arteriovenous fistulas with long-term persistent cortical venous reflux. Stroke 33:12331236,2002

71. Voorberg J, Roelse J, Koopman R, Buller H, Berends F, ten Cate JW, et al: Association of idiopathic venous thromboembolism with single point-mutation at Arg506 of factor V. Lancet 343:1535-1536, 1994

72. Wenderoth JD, Phatouros CC: Incidental discovery of a dural arteriovenous fistula in a patient with activated protein $\mathrm{C}$ resistance. AJNR Am J Neuroradiol 24:1369-1371, 2003

73. Wilson CB: Cryptic vascular malformations. Clin Neurosurg 38:49-84, 1992

74. Witt O, Pereira PL, Tillmann W: Severe cerebral venous sinus thrombosis and dural arteriovenous fistula in an infant with protein S deficiency. Childs Nerv Syst 15:128-130, 1999

75. Wolfe SQ, Heros RC: Developmental venous anomalies with arterial supply. J Neurosurg 108:1139-1141, 2008

76. Wurm G, Schnizer M, Fellner FA: Cerebral cavernous malformations associated with venous anomalies: surgical considerations. Neurosurgery 57:42-58, 2005

77. Zuber M, Toulon P, Marnet L, Mas JL: Factor V Leiden mutation in cerebral venous thrombosis. Stroke 27:1721-1723, 1996

Manuscript submitted July 15, 2009.

Accepted August 26, 2009.

Address correspondence to: Giuseppe Lanzino, M.D., Department of Neurologic Surgery, Mayo Clinic, 200 First Street SW, Rochester, Minnesota 55905. email: lanzino.giuseppe@ mayo.edu. 